
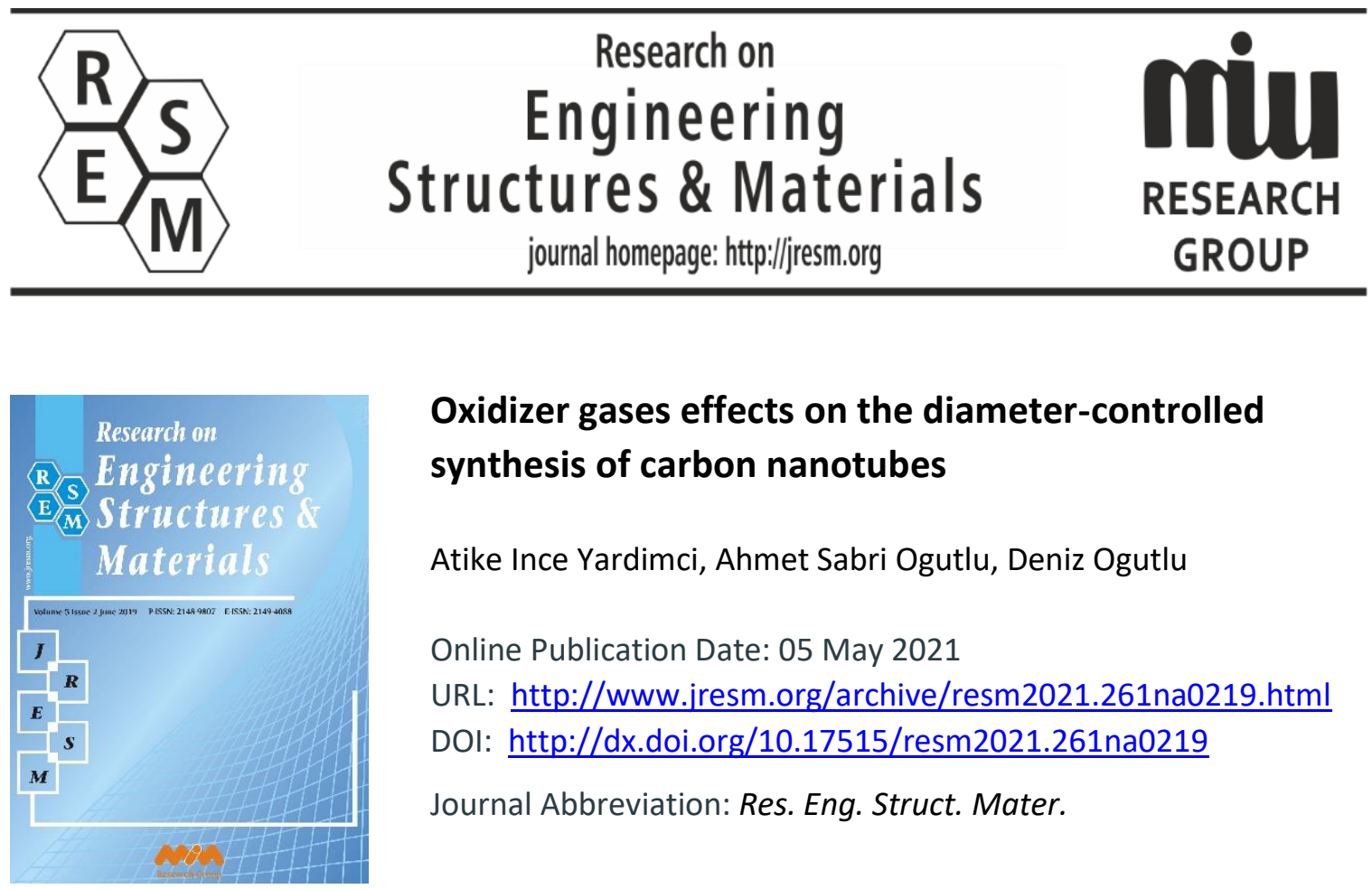

\title{
Oxidizer gases effects on the diameter-controlled synthesis of carbon nanotubes
}

Atike Ince Yardimci, Ahmet Sabri Ogutlu, Deniz Ogutlu

Online Publication Date: 05 May 2021

URL: http://www.jresm.org/archive/resm2021.261na0219.html

DOI: http://dx.doi.org/10.17515/resm2021.261na0219

Journal Abbreviation: Res. Eng. Struct. Mater.

\section{To cite this article}

Yardimici Al, Ogutlu AS, Ogutlu D. Oxidizer gases effects on the diameter-controlled synthesis of carbon nanotubes. Res. Eng. Struct. Mater., 2021; 7(3): 331-346.

\section{Disclaimer}

All the opinions and statements expressed in the papers are on the responsibility of author(s) and are not to be regarded as those of the journal of Research on Engineering Structures and Materials (RESM) organization or related parties. The publishers make no warranty, explicit or implied, or make any representation with respect to the contents of any article will be complete or accurate or up to date. The accuracy of any instructions, equations, or other information should be independently verified. The publisher and related parties shall not be liable for any loss, actions, claims, proceedings, demand or costs or damages whatsoever or howsoever caused arising directly or indirectly in connection with use of the information given in the journal or related means.

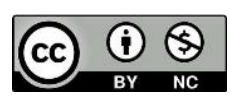

Published articles are freely available to users under the terms of Creative Commons Attribution - NonCommercial 4.0 International Public License, as currently displayed at here (the "CC BY - NC"). 


\title{
Research on Engineering Structures \& Materials
}

journal homepage: http://jresm.org

\section{Oxidizer gases effects on the diameter-controlled synthesis of carbon nanotubes}

\author{
Atike Ince Yardimci1,2,a, ${ }^{*}$, Ahmet Sabri Ogutlu ${ }^{3, b}$, Deniz Ogutlu ${ }^{4, c}$ \\ ${ }_{1}^{1}$ Department of Material Science and Engineering İzmir Institute of Technology, Urla, Izmir, Turkey \\ ${ }^{2}$ Technology Transfer Office, Usak University, Usak, Turkey \\ ${ }^{3}$ Department of Industrial Engineering Harran University, Haliliye, Sanliurfa, Turkey \\ ${ }^{4}$ Department of Physics İmir Institute of Technology, Urla, Izmir, Turkey
}

\begin{abstract}
Article Info Abstract
Article history:

Received 19 Feb 2021

Revised 02 May 2021

Accepted 03 May 2021

Keywords:

Carbon nanotube; Chemical Vapour; Deposition;

Diameter Control; Fe Catalyst

In this study, the influence of the oxidizers on the synthesis of carbon nanotubes by $\mathrm{C}_{2} \mathrm{H}_{4}$ decomposition over Fe catalyst has been investigated. $\mathrm{CO}_{2}, \mathrm{O}_{2}$, and $\mathrm{H}_{2} \mathrm{O}$ have been used as oxidizers, and to control catalyst particle formation and their sizes in the pretreatment stage. The same oxidizers have also been used in the growth stage to maintain the catalyst particle size, remove amorphous carbon formation to keep catalyst particle active. The results of scanning electron microscopy indicated that the average diameters of nanotubes decreased from $13.4 \pm 1.2 \mathrm{~nm}$ to $6.2 \pm 0.5 \mathrm{~nm}$ and extremely dense nanotubes were obtained when we added a small amount of $\mathrm{CO}_{2}$. Adding $\mathrm{O}_{2}$ extremely decreased the areal carbon nanotube density while widens the diameter distribution. $\mathrm{H}_{2} \mathrm{O}$ addition resulted in larger average diameters and made the growth strongly pretreatment dependent. Within the parameters tried for catalyst pretreatment and CNT growth processes, $\mathrm{CO}_{2}$ seemed the best choice for a weak oxidizing assistant. The strong dependency of the average diameter on pretreatment conditions indicated that pretreatment is a very important step in deciding the final diameters and their distribution.
\end{abstract}

(C) 2021 MIM Research Group. All rights reserved.

\section{Introduction}

Carbon nanotubes (CNTs), due to their superior mechanical and physical properties [1], are undoubtedly one of the most promising nanomaterials for the growing number of applications in the nanotechnology era [2]. The distinctive characteristic properties of carbon nanotubes stem from the size of these materials and their atomic structure. Nanotubes can be either metals or semiconductors depending on their various helicity structure and diameters [3]. Also, the diameters of CNTs significantly affect their mechanical properties and thus influence their applications. Some of the applications to highly these growing areas include field emission device [4,5], scanning probe [6-8], sensors [9, 10], high strength composite [11], and supercapacitors [12-14].

On the other hand, the growth process and controlling mechanisms of the CNTs are still not completely understood. Chemical Vapour Deposition (CVD) is the growth technique that allows control of the growth to a certain extent and it is scalable to industrial needs. All of the CVD techniques require catalyst nanoparticles for the growth of CNTs. The size of the catalyst particles which are usually chosen from transition metals plays an important role in determining the diameters of CNTs. These catalyst particles can be obtained using various techniques. Among these, the ones grown on a substrate [15] are crucially important since they will be building the bridge between microelectronics and nanotechnology. These very thin films (1-2 $\mathrm{nm})$ will oxidize immediately once they are

\footnotetext{
${ }^{*}$ Corresponding author: tekin.3@osu.edu

a orcid.org/0000-0001-5482-4230; b orcid.org/0000-0003-1634-0600; c orcid.org/0000-0003-3135-6547 DOI: http://dx.doi.org/10.17515/resm2021.261na0219
} 
exposed to air till CNT growth. Most assume that the effective CNT growth proceeds after metal oxide to metal reduction. It is also known that metal oxide does not coalesce completely without the reduction.

For the reduction, various oxidizers [16-18] besides hydrogen [19-21] have recently been used to adjust the reaction rate and etch away the amorphous carbon deposition during the CNT growth $[22,23]$. The reduction pretreatment step and its duration are significant in defining CNT characteristics. If the pretreatment time was kept too long, the catalyst particles would have wider size distribution and larger sizes [24] due to the high temperatures needed for growth. It would lead to nanofiber formation having larger diameters and inferior characteristics compare to CNTs. All these indicators point that the reduction pretreatment and the growth start timing are the deciding factors in CNT formation. Based on this concept, there are significant efforts to optimize CNT growth conditions.

Recent efforts have focused on the oxidizers as the growth enhancers and optimization of forest growth related to CNT yields and heights in the presence of weak oxidizers [25]. Even though those are very important to improve for industrial applications, their diameters and keeping diameter distribution tightly narrow usually have not been paid enough attention. The diameter is the most important parameter in CNT production since it will be deciding the CNT characteristics [26]. For the diameter control, the thickness of the catalyst film is a good starting point however with the process parameters the diameter distribution can readily go off track.

Effective CNT growth was studied in different studies $[27,28]$ and these studies indicated that the presence of $\mathrm{CO}_{2}$ caused a domed CNT growth, and the height of CNT distributes was more uniformly and converted to radial block figure. CNT structures such as dishes were obtained by increasing line heights with the increased amount of $\mathrm{CO}_{2}$. Different CNT morphologies occurred with the increase of $\mathrm{CO}_{2}$ amount because of the change of CNT growth velocity and change of bonding force between CNT and support material. Futuba et al. studied $\mathrm{H}_{2} \mathrm{O}$ vapor, acetone, ethanol, metilbenzoat, and $\mathrm{CO}_{2}$ was used to improve CNT growth by etching amorphous carbon in catalysts particle poisoned. Their results indicated that from these enhancers $\mathrm{H}_{2} \mathrm{O}$ provided the best CNT growth atmosphere among these gases and the highest CNTs were obtained with $\mathrm{H}_{2} \mathrm{O}$. Carpet height CNT arrays at some samples terminated after one minute. Li et all. indicated that the heights of CNT grown with the addition of air continuous to not decrease till $500 \mathrm{~min}$. Average CNT diameters were $35 \mathrm{~nm}$ close areas of buffer layer and $100 \mathrm{~nm}$ up of buffer layer were obtained. These diameter values showed that the structure of CNTs was closer to fiber than a cylindrical structure [29]. $\mathrm{CO}_{2}$ oxygenizes the amorphous carbon in CNT synthesis process, and hence the catalyst stays active longer time, and therefore length and yield of CNTs increase. Besides, $\mathrm{CO}_{2}$ can be decomposed on the catalyst clusters surface and reacts with other molecules and radicals, resulting in intermediates that can be more effective for the CNT growth. However, in this present study, oxidizers were utilized to control catalyst size and hence CNT diameters. Besides, diameter distributions were 2-3 nm in terms of standard deviation. This value was similar to the diameters distribution of SWNT obtained in the literature [30].

This study aims to analyze and determine the role of oxidizer gases during both catalyst pretreatment and CNT growth processes. The effects of the ratios of oxidizer gases in pretreatment to those in growth, time of oxidizer gas introduction in pretreatment process, and CNT growth temperature on CNT morphologies. $\mathrm{CO}_{2}, \mathrm{O}_{2}$, and $\mathrm{H}_{2} \mathrm{O}$ were used in small amounts as oxidizers. The main aim was to utilize oxidizers to control catalyst particle size during the reducing pretreatment process and the growth process at the same time 
preventing amorphous carbon deposition over the outer walls of CNTs and catalyst particles.

All as-grown samples were characterized by scanning electron microscopy (SEM), CNT diameters were measured and diameters distributions were obtained. CNT diameters within very narrow ranges were controlled. The growth with $\mathrm{CO}_{2}$ yielded samples with better characteristics. Lower CNT density was observed by using $\mathrm{O}_{2}$ compared to the other oxidizers. Using oxidizers both in the pretreatment and in the growth, stages helped to keep wider metal catalyst sizes and hence CNT diameters in narrow ranges which lead to effective CNT growth.

\section{Experimental Section}

In this study, $\mathrm{Fe}$ thin films were utilized as the catalyst material for CNT growth. $\mathrm{Fe} / \mathrm{Al}_{2} \mathrm{O}_{3} / \mathrm{SiO}_{2}$ Commercially purchased $\mathrm{Si}$ substrates were utilized as a support layer and cleaned in methanol by rinsing for $15 \mathrm{~min}$ in an ultrasonic bath and then in ultra-pure water for $15 \mathrm{~min}$. Cleaned silicon substrates were oxidized by a dry thermal oxidation system. 10-15 nm thick Al2O3 and then 1.0-1.5 nm thick Fe layers were deposited on $\mathrm{SiO} 2$ substrate by DC magnetron sputtering technique. In the sputtering process, base pressure was $1 \times 10^{-6}$ Torr prior to catalyst film growth while film growth was carried out at a deposition rate of $0.1 \mathrm{Ao} / \mathrm{s}, 20 \mathrm{~W}$, and a growth pressure of $0.5 \mathrm{mTorr}$.

The thermal chemical vapor deposition (CVD) method was used for the CNT growth process. In a typical experiment, $4 \times 4 \mathrm{~mm} 2 \mathrm{Fe} / \mathrm{Al}_{2} \mathrm{O}_{3} / \mathrm{SiO}_{2}$ thin film samples were put into a quartz boat and placed in the middle of the quartz tube and the CVD furnace was heated to $760^{\circ} \mathrm{C}$. Experiments were carried out at atmospheric pressure. $\mathrm{C}_{2} \mathrm{H}_{4}$ was utilized as a carbon source and Ar was used as the carrier gas to carry the oxide gases to the reaction chamber. At a growth temperature of $760^{\circ} \mathrm{C}$, gas flows were then switched to $\mathrm{C}_{2} \mathrm{H}_{4}$, oxide gases $\left(\mathrm{CO}_{2}, \mathrm{O}_{2}, \mathrm{H}_{2} \mathrm{O}\right)$, and $\mathrm{H} 2$ for the desired growth time. The total gas flow was kept at 250 sccm at growth. Different gas flow rates and pretreatment times for oxidizers were investigated. The flow rates of other gases were constant in all experiments and $150 \mathrm{sccm}$ for Ar gas, $140 \mathrm{sccm}$ for $\mathrm{H}_{2}$ gas, and $180 \mathrm{sccm}$ for $\mathrm{C}_{2} \mathrm{H}_{4}$ gases. After growth, $\mathrm{C}_{2} \mathrm{H}_{4}, \mathrm{H}_{2} \mathrm{O}$, and $\mathrm{H} 2$ flows were turned off and CNTs were kept to cool down to ambient temperature under Ar flow with a flow rate of $150 \mathrm{sccm}$.

In order to analyze the morphology of CNTs scanning electron microscopy (SEM) was utilized. The quality and type of CNTs were examined with Raman Spectroscopy with HeNe laser with the excitation wavelength of $632.8 \mathrm{~nm}$.

\section{Results and Discussion}

One of the primary objectives of this study was to examine various oxidizers effects in the catalyst pretreatment and CNT growth stages. It has been suggested that "weak" oxidizers play a sanitary role by etching away amorphous carbon accumulation over catalyst particles which poison them and, thus, extending their life so that they can remain active longer for CNT growth [31]. This way highly efficient growth could be achieved. To do this, we studied four different pretreatment times and various amounts of $\mathrm{CO}_{2}, \mathrm{O}_{2}, \mathrm{H}_{2} \mathrm{O}$. We continued to send the smaller amount of oxidizers during growth time. Consequently, we reached narrow diameter distributions in the presence of various oxidizers. Standard deviations and standard errors of the average CNT diameters were analyzed and standard deviations of all samples were obtained in the range of 1-2 nm. The standard error of the average CNT diameter was found moderately small. 


\subsection{The role of $\mathrm{CO}_{2}$ for effective $\mathrm{CNT}$ growth}

In this study, influences of $\mathrm{CO}_{2}$ were analyzed on a variety of growth conditions to control CNT diameter at a constant CNT growth temperature. SEM images were utilized to analyze CNT diameter and more than 70 tubes diameter were counted for each sample.

\subsubsection{Catalyst pretreatment time effect}

The effect of $\mathrm{CO}_{2}$ in the CNT growth using $\mathrm{C}_{2} \mathrm{H}_{4}$ as a carbon source was studied by changing both pretreatment time and $\mathrm{CO}_{2}$ level using the $\mathrm{Fe} / \mathrm{Al}_{2} \mathrm{O}_{3} / \mathrm{SiO}_{2}$ thin film as catalyst material and a smaller amount of $\mathrm{CO}_{2}$ proceeded to be sent during CNT growth. Four different pretreatment times were tested in this part of the study and these were 2, 5, 10, 15 minutes. Besides, $\mathrm{CO}_{2}$ flow rates were sent into the CVD system during both catalyst pretreatment and CNT growth as 10:1, 10:2, 5:1, 5:2, 2:1, and 2:2 sccm, respectively. The effects of $\mathrm{CO}_{2}$ under growth conditions were investigated by SEM images of CNTs. The catalyst particle sizes were increasing with increased pretreatment time at the ratios of 10:1 and 5:1 gas flow.

This growth carried possibly out converting elemental form after the reduction of metaloxide to metal film with $\mathrm{H}_{2}$ and $\mathrm{CO}_{2}$ controlled the reduction velocity of the metal oxide film.

Catalyst immediately clustered with the effect of high temperature on the elemental metal form and especially the $\mathrm{SiO}_{2}$ layer. Also, these clusterings were active on the surface and occurred larger nanoparticles the results of collisions with others during these motions. Large nanoparticle influence negatively CNT growth, they decreased the density of CNT at the unit area. Here are significant amounts of $\mathrm{H}_{2}$ and $\mathrm{CO}_{2}$. The results showed that ideal particle sizes were obtained by adjusting both pretreatment time and $\mathrm{CO}_{2}$ level (Table 1 ).

Once we carefully examined that the samples of CNTs exposed to shorter pretreatment time have more uniformity, smaller average diameters, and more density of growth. This supported our events that longer pretreatment time caused more growth of catalyst particles. Once we looked from the sides and anglely (Fig. 1), we observed that 15 and 10 min. samples include much more space than samples of 5 and 2 min. This state could be explained by decreased density of CNTs by forming bigger particles of the catalyst particle. When we calculated diameter, CNT diameters change among $5 \mathrm{~nm}-8 \mathrm{~nm}$ at short pretreatment time.

The dependence of CNT diameters on pretreatment time was analyzed in detail and the results were given in Fig. 2 . A high concentration of $\mathrm{CO}_{2}(10 \mathrm{sccm})$ during the pretreatment process and short pretreatment time resulted in larger CNT diameters without depending on $\mathrm{CO}_{2}$ amount during growth time. When pretreatment time was increased at high amounts of $\mathrm{CO}_{2}$, diameters of the CNTs grown under $2 \mathrm{sccm} \mathrm{CO}_{2}$ were directly decreased. However, at growth time, diameters of CNTs grown under $1 \mathrm{sccm} \mathrm{CO}_{2}$ were increasing because in the presence of high $\mathrm{CO}_{2}$, reduction of metal oxide to metal was not completely achieved, therefore large nanoparticle clustered and CNT diameter got larger. CNT diameter decreased with pretreatment time because samples were grown at high $\mathrm{CO}_{2}$ during pretreatment time and $2 \mathrm{sccm} \mathrm{CO} 2$ during growth prevented sufficient oxygen and smaller catalyst particle growth occurred.

The studies with low $\mathrm{CO}_{2}$ during pretreatment time supported that $2 \mathrm{sccm} \mathrm{CO}_{2}$ flow rate provided smaller diameters than $1 \mathrm{sccm} \mathrm{CO}_{2}$ flows during growth time. 
Table 1 Catalyst pretreatment and CNT growth parameters and average CNT diameters in the presence of $\mathrm{CO}_{2} / \mathrm{H}_{2}$ for both different pretreatment times and growth times (CNT Growth temperature: $740{ }^{\circ} \mathrm{C}$ ).

\begin{tabular}{cccc}
\hline Sample & $\begin{array}{c}\text { Pretreatment } \\
\text { time (min.) }\end{array}$ & $\begin{array}{c}\mathrm{CO}_{2}(\mathrm{p}) / \mathrm{CO}_{2}(\mathrm{~g}) \\
(\mathrm{sccm})\end{array}$ & $\begin{array}{c}\text { Ave. diameters } \\
(\mathrm{nm})\end{array}$ \\
\hline CNT1 & 15 & $10 / 1$ & 12.5 \\
CNT2 & 10 & $10 / 1$ & 10.0 \\
CNT3 & 5 & $10 / 1$ & 9.5 \\
CNT4 & 2 & $10 / 1$ & 8.8 \\
CNT5 & 15 & $10 / 2$ & 6.1 \\
CNT6 & 10 & $10 / 2$ & 6.7 \\
CNT7 & 5 & $10 / 2$ & 6.8 \\
CNT8 & 2 & $10 / 2$ & 11.2 \\
CNT9 & 15 & $5 / 1$ & 9.8 \\
CNT10 & 10 & $5 / 1$ & 9.3 \\
CNT11 & 5 & $5 / 1$ & 8.9 \\
CNT12 & 2 & $5 / 1$ & 6.1 \\
CNT13 & 15 & $5 / 2$ & 5.7 \\
CNT14 & 10 & $5 / 2$ & 6.3 \\
CNT15 & 5 & $5 / 2$ & 7.3 \\
CNT16 & 2 & $5 / 2$ & 7.3 \\
\hline
\end{tabular}

\subsubsection{Temperature effect}

The temperature effect in $\mathrm{CO}_{2}$-assisted CVD was studied for four different pretreatment times at two different growth temperatures. $\mathrm{CO}_{2}$ effects with a flow rate of $2 \mathrm{sccm}$ at different growth temperatures were investigated. The results showed that average diameters were ranging between $15-29 \mathrm{~nm}$ at $740{ }^{\circ} \mathrm{C}$ and $5-8 \mathrm{~nm}$ at $760{ }^{\circ} \mathrm{C}$ (Table 2). High CNT growth temperature provided thinner nanotubes.

Carbon-oxygen reaction resulted in $\mathrm{CO}$ owing to catalyst particle metal oxide form [32]. If catalyst particle did not keep suitable pretreatment time and growth parameters, then catalyst surface is coated by amorphous carbon and CNT formation did not occur. The coming gas amount should be optimized and mixed with an appropriate amount of $\mathrm{H}_{2}$.

It was expected that film coalesces by removing from the surface with the effect of temperature and hydrogen and catalyst nanoparticles properly spread the whole surface. Uniform and small particle size was necessary for efficient CNT growth.

The Fe particles were expected to diffuse uniformly on the whole surface and coalesce removing the surface with the effect of temperature and hydrogen. The temperature was more important in this situation. The coalescence was carried out after the metal oxide film 
was converted to the metal film. During pretreatment, $\mathrm{CO}_{2}$ provided controlled coalescences by controlling the speed of this translation. Also, $\mathrm{CO}_{2}$ assisted to remove amorphous carbon that forms throughout CNT growth. Our results showed that particle size decreased with increasing temperature because more effectively reduced metal oxide form to metal form with increased temperature. At this state converter particle state from the film was easier.

By using $\mathrm{H}_{2}$ and $\mathrm{CO}_{2}$, smaller CNT diameters and more density CNTs were obtained at high temperatures when compared to 740 and $760{ }^{\circ} \mathrm{C}$ (Figure3). CNT growth temperatures of 740 and $760{ }^{\circ} \mathrm{C}$ displayed similar behavior depending on pretreatment time. Temperature is also a significant parameter to determine CNT diameters, as well as $\mathrm{CO}_{2}$.

According to SEM analysis results (Fig. 4) CNT density on the surface was rare and diameters change between $15-20 \mathrm{~nm}$ at $740{ }^{\circ} \mathrm{C}$. However, at $760{ }^{\circ} \mathrm{C}$, growth on the surface enhanced and the average diameter of CNTs decreased to the range of 5-6 $\mathrm{nm}$ at $760{ }^{\circ} \mathrm{C}$.

Fig. 5 showed the relationship between average CNT diameter and pretreatment time for the growths carried out at 740 and $760^{\circ} \mathrm{C}$. The results indicated that firstly, CNT diameters were increasing with increasing pretreatment time and then slowly decreasing for pretreatment time of $10: 1 \mathrm{sccm}$. Average diameters of both short pretreatment time and $\mathrm{CO}_{2}$ level of $1 \mathrm{sccm}$ were smallest. At large parts of $1 \mathrm{sccm}$ oxidizer, this identified that catalyst nanoparticle clustering through high temperature could not prevent more large catalyst particles to occur.

\subsubsection{Effect of discontinuous catalyst pretreatment}

CO2 effect on CNT growth with thermal CVD has investigated the states that the pretreatment duration of $\mathrm{CO}_{2}$ was shorter than $\mathrm{H}_{2}$. $\mathrm{CO}_{2}$ flow rates were 10:1, 10:2, 5:2, 5:1, $2: 2$ ve $2 / 1 \mathrm{sccm}$ and pretreatment time for $\mathrm{H} 2$ was studied 15 and $10 \mathrm{~min}$., pretreatment time for $\mathrm{CO}_{2}$ was studied for 5 and 2 min. (Table 3). Diameters chanced between $5-8 \mathrm{~nm}$. Shorter $\mathrm{CO}_{2}$ pretreatment time according to $\mathrm{H}_{2}$ caused by keeping a narrow range of the diameters (Figure 6).
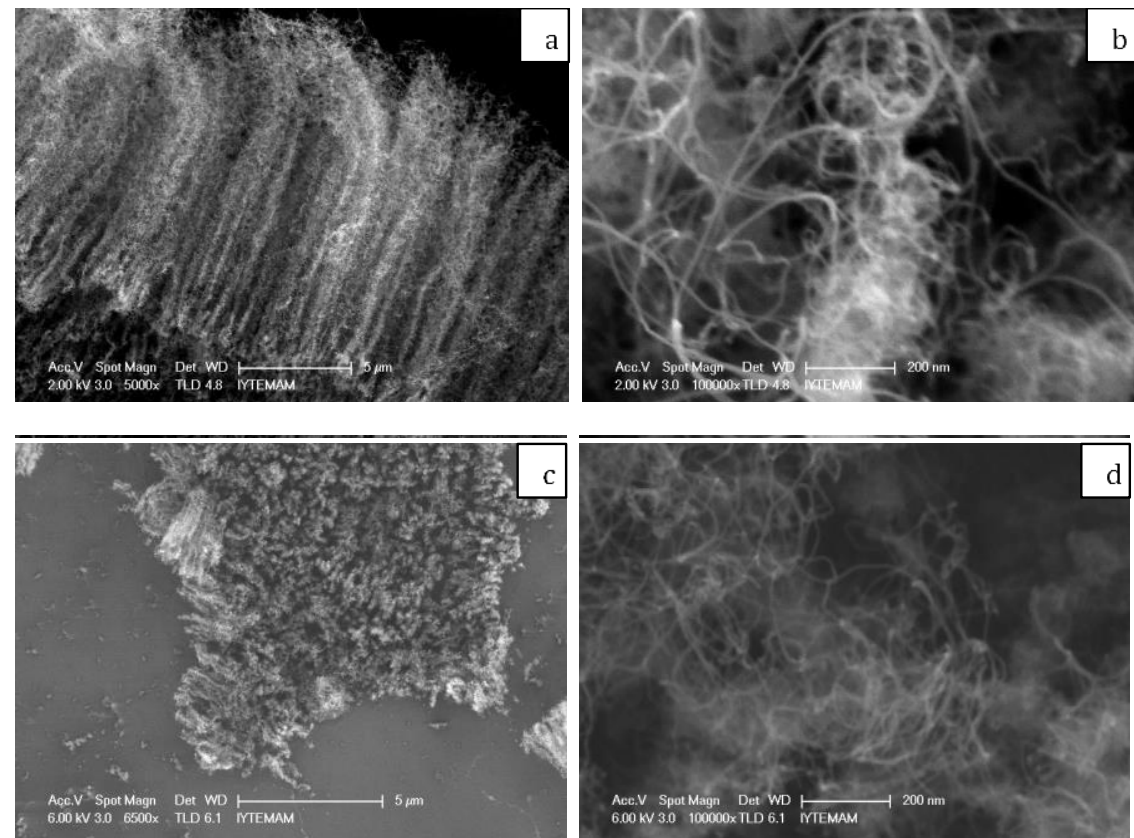

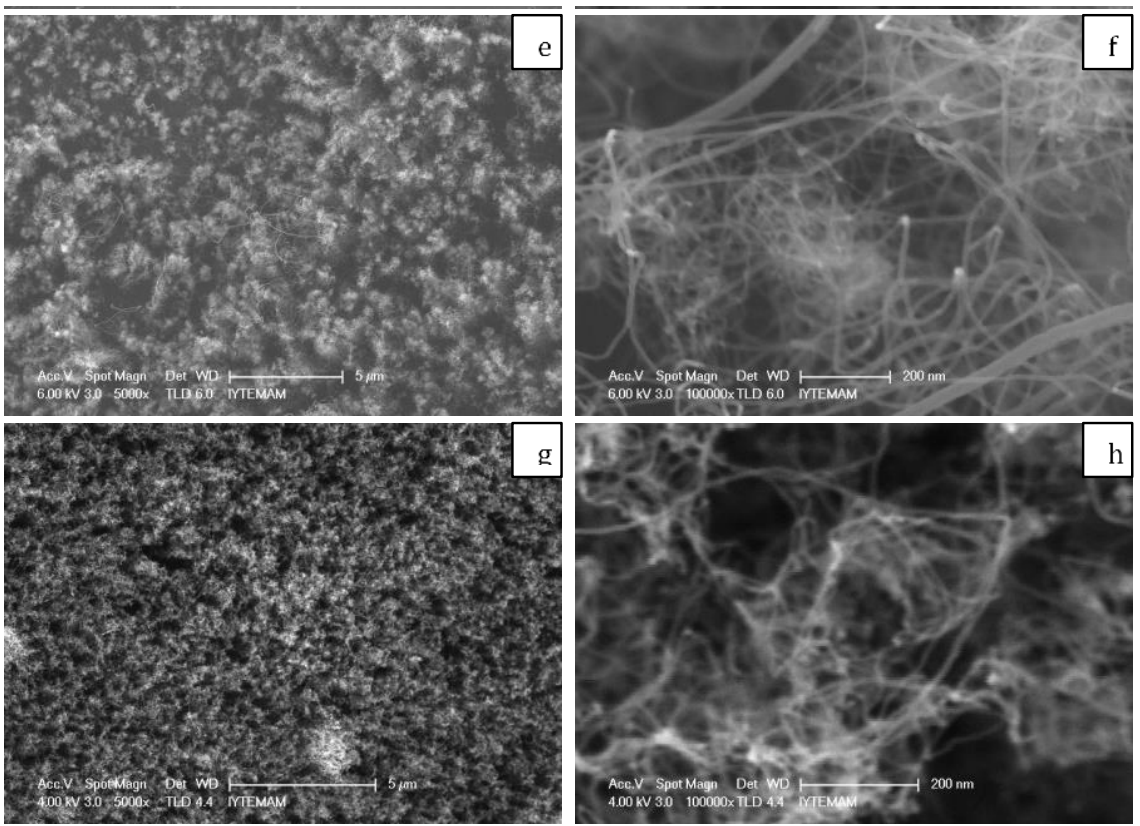

Fig. 1 SEM images of the nanotubes grown with $\mathrm{CO} 2$ as oxidizer at $740^{\circ} \mathrm{C}$ for different pretreatment times a), b) CNT1 15 min. , c), d) CNT2 10 min. , e), f) CNT3 5 min. , g), h) CNT4 2min

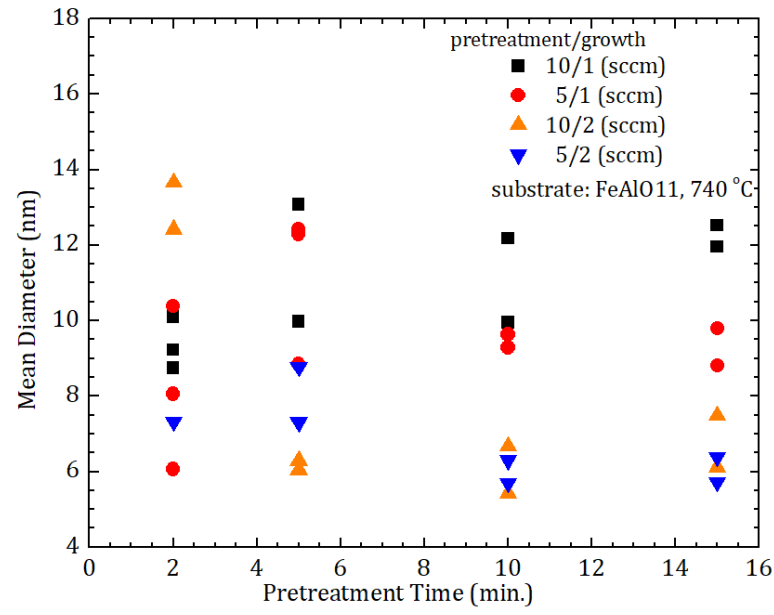

Fig. 2. Dependence of obtained average values of diameters on pretreatment time and $\mathrm{CO}_{2}$ ratio 
Table 1. Catalyst pretreatment and CNT growth parameters and average CNT diameters in the presence of $\mathrm{CO}_{2} / \mathrm{H}_{2}$ at different temperatures

\begin{tabular}{|c|c|c|c|c|}
\hline Sample & $\begin{array}{c}\text { Temperature } \\
\left({ }^{\circ} \mathrm{C}\right)\end{array}$ & $\begin{array}{l}\text { Pretreatment } \\
\text { time (min.) }\end{array}$ & $\mathrm{CO}_{2} / \mathrm{H}_{2}(\mathrm{sccm})$ & $\begin{array}{c}\text { Ave. } \\
\text { diameters(nm) }\end{array}$ \\
\hline CNT17 & 740 & 15 & $2 / 140$ & 20.74 \\
\hline CNT18 & 740 & 10 & $2 / 140$ & 18.57 \\
\hline CNT19 & 740 & 5 & $2 / 140$ & 17. 36 \\
\hline CNT20 & 740 & 2 & $2 / 140$ & 21.91 \\
\hline CNT21 & 760 & 15 & $2 / 140$ & 6.77 \\
\hline CNT22 & 760 & 10 & $2 / 140$ & 5.72 \\
\hline CNT23 & 760 & 5 & $2 / 140$ & 5.12 \\
\hline CNT24 & 760 & 2 & $2 / 140$ & 6.10 \\
\hline
\end{tabular}

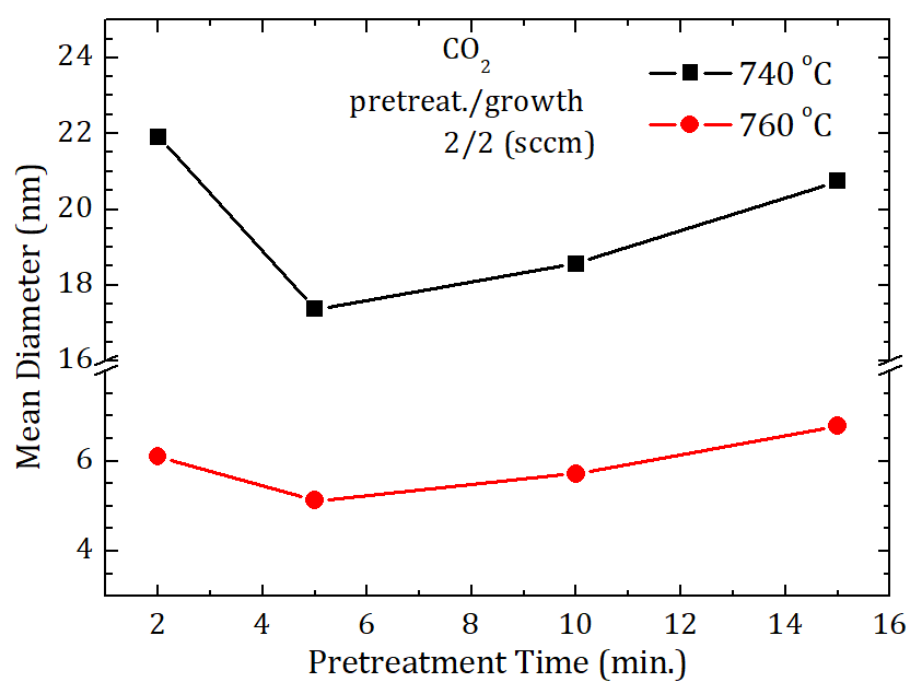

Fig. 3. Mean CNT diameters vs. catalyst pretreatment time for 740 and $760{ }^{\circ} \mathrm{C}, \mathrm{CO}_{2}$ flow rate: $2 \mathrm{sccm}$ and $2 \mathrm{sccm}$ during pretreatment and growth processes, respectively 

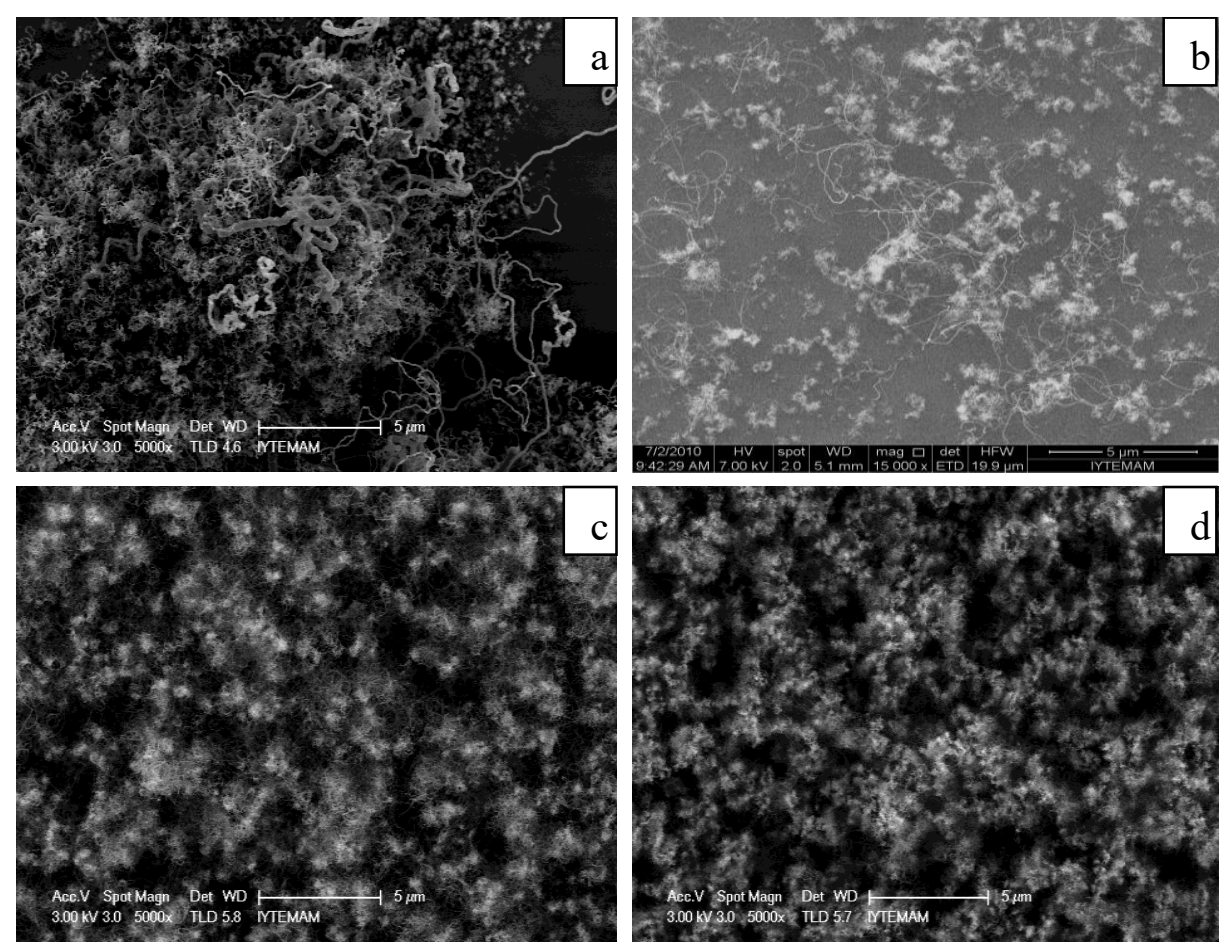

Fig. 4. SEM images of CNTs grown with $\mathrm{CO}_{2}$, a) $740^{\circ} \mathrm{C}, \mathrm{CNT} 17,15 \mathrm{~min}$. b) $740^{\circ} \mathrm{C}$, CNT18, 10 min. c) $760^{\circ} \mathrm{C}$, CNT21, 15 min. d) $760^{\circ} \mathrm{C}, \mathrm{CNT} 23,5 \mathrm{~min}$

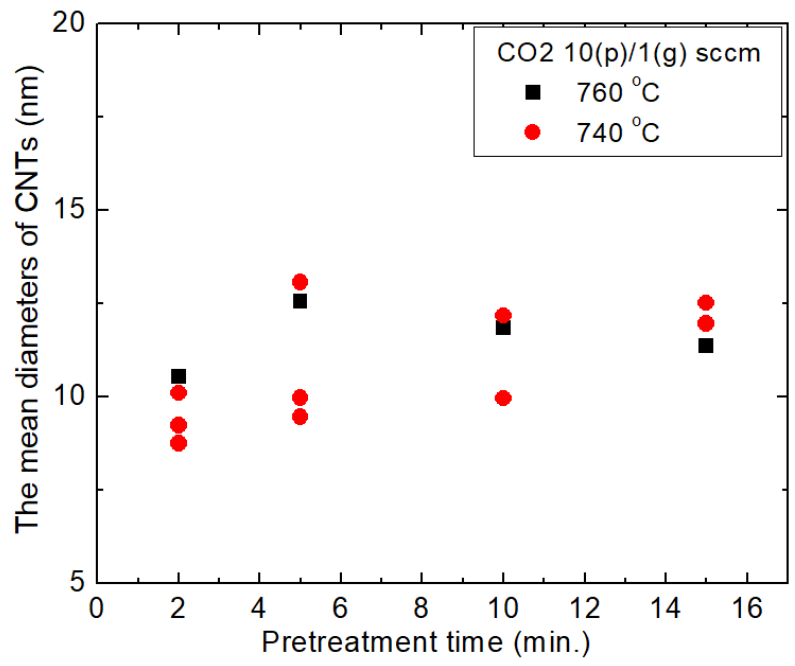

Fig. 5. Mean CNT diameter vs. catalyst pretreatment time, $\mathrm{CO}_{2}$ flow rate: $10 \mathrm{sccm}$ and 1 sccm during pretreatment and growth processes, respectively 
Table 2. Catalyst pretreatment and CNT growth parameters and average CNT diameters in the presence of $\mathrm{CO}_{2}+\mathrm{H}_{2}$ gases for different pretreatment time (CNT Growth temperature: $760^{\circ} \mathrm{C}$ )

\begin{tabular}{cccc}
\hline Sample & $\begin{array}{c}\text { Pretreatment }(\mathrm{min}) \\
\mathrm{H}_{2} / \mathrm{CO}_{2}\end{array}$ & $\begin{array}{c}\mathrm{CO}_{2}(\mathrm{p}) / \mathrm{CO}_{2}(\mathrm{~g}) \\
(\mathrm{sccm})\end{array}$ & $\begin{array}{c}\text { Ave. } \\
\text { diameters } \\
(\mathrm{nm})\end{array}$ \\
\hline CNT25 & $15 / 5$ & $10 / 2$ & 5.96 \\
CNT26 & $15 / 10$ & $10 / 1$ & 8.07 \\
CNT27 & $15 / 2$ & $10 / 1$ & 6.60 \\
CNT28 & $15 / 2$ & $5 / 2$ & 7.02 \\
CNT29 & $15 / 5$ & $5 / 1$ & 7.50 \\
CNT30 & $15 / 2$ & $2 / 2$ & 5.45 \\
CNT31 & $10 / 5$ & $10 / 2$ & 6.82 \\
CNT32 & $10 / 5$ & $5 / 2$ & 4.69 \\
CNT33 & $10 / 5$ & $2 / 1$ & 7.29 \\
CNT34 & $5 / 2$ & $5 / 1$ & 8.90 \\
\hline
\end{tabular}

\subsection{The role of $\mathrm{O}_{2}$ for effective CNT growth}

The effect of $\mathrm{O}_{2}$ for effective CNT growth with $\mathrm{C}_{2} \mathrm{H}_{4}$-CVD technique on the $\mathrm{Fe} / \mathrm{Al}_{2} \mathrm{O}_{3} / \mathrm{SiO}_{2}$ thin film was investigated for different pretreatment times and different $\mathrm{O}_{2}$ flow rates. Examined pretreatment times were 15, 10, 5, 2 minutes. Studied $\mathrm{O}_{2}$ flow rates during catalyst pretreatment and CNT growth were 5:1, 5:2, 2:2, 2:0.5, respectively. SEM images showed that $\mathrm{Fe} / \mathrm{Al}_{2} \mathrm{O}_{3} / \mathrm{SiO}_{2}$ thin film samples exposed to $\mathrm{O}_{2}$ gas flow of 5:2, 5:1, 2:2, 2:0.5 sccm, resulted in larger CNT diameters while pretreatment time decreased. This growth carried out translating elemental form by removing the oxide via $\mathrm{H}_{2}$ the catalyst being metal-oxide form. As a result, small CNT diameters ranging between $6-8 \mathrm{~nm}$ at the pretreatment time of 15 minutes were obtained in the presence of $\mathrm{O}_{2}$. Average CNT diameters for pretreatment times of 10, 5, 2 min. were in the range of 9-14 $\mathrm{nm}$ (Table 4).

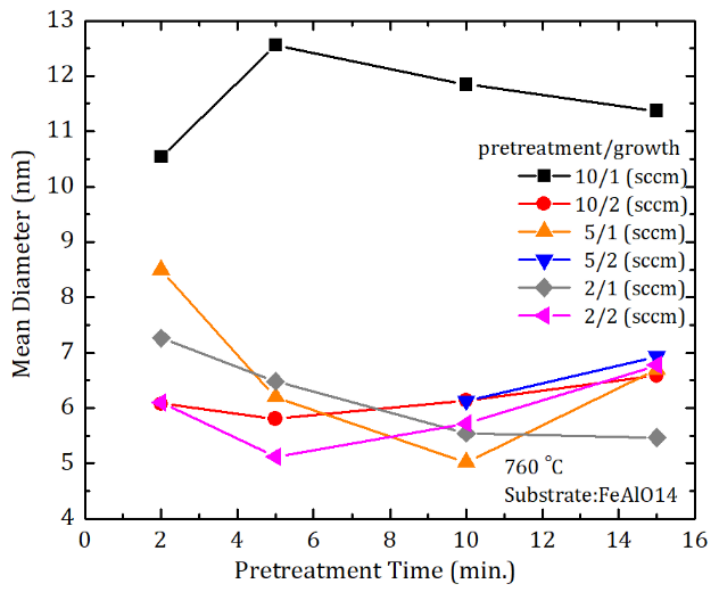

Fig. 6. Mean CNT diameter vs. catalyst pretreatment time for different pretreatment/growth $\mathrm{CO}_{2}$ amount at growth temperature of $760{ }^{\circ} \mathrm{C}$ 
Table 3. Catalyst pretreatment and CNT growth parameters in the presence of $\mathrm{O}_{2}$ for different pretreatment times (P: $1 \mathrm{~atm} ., \mathrm{T}: 760^{\circ} \mathrm{C}$, Ar: $150 \mathrm{sccm} \mathrm{H}_{2}: 140 \mathrm{sccm}$ ).

\begin{tabular}{cccccc}
\hline \multirow{2}{*}{$\begin{array}{c}\text { Sample } \\
\text { name }\end{array}$} & \multicolumn{2}{c}{ Pretreatment } & \multicolumn{3}{c}{ CNT Growth } \\
\cline { 2 - 6 } & $\begin{array}{c}\mathrm{O}_{2} \\
(\mathrm{sccm})\end{array}$ & $\begin{array}{c}\text { Time } \\
\text { (min. })\end{array}$ & $\begin{array}{c}\mathrm{C}_{2} \mathrm{H}_{4} \\
(\mathrm{sccm})\end{array}$ & $\begin{array}{c}\mathrm{O}_{2} \\
(\mathrm{sccm})\end{array}$ & $\begin{array}{c}\text { Time } \\
\text { (min.) }\end{array}$ \\
\hline CNT35 & 5 & 15 & 180 & 2 & 15 \\
CNT36 & 5 & 10 & 180 & 2 & 15 \\
CNT37 & 5 & 5 & 180 & 2 & 15 \\
CNT38 & 5 & 2 & 180 & 2 & 15 \\
CNT39 & 5 & 15 & 180 & 1 & 15 \\
CNT40 & 5 & 10 & 180 & 1 & 15 \\
CNT41 & 5 & 5 & 180 & 1 & 15 \\
CNT42 & 5 & 2 & 180 & 1 & 15 \\
CNT43 & 2 & 15 & 180 & 2 & 15 \\
CNT44 & 2 & 10 & 180 & 2 & 15 \\
CNT45 & 2 & 10 & 180 & 2 & 15 \\
CNT46 & 2 & 15 & 180 & 0.5 & 15 \\
CNT47 & 2 & 5 & 180 & 0.5 & 15 \\
CNT48 & 0.5 & 15 & 180 & - & 15 \\
CNT49 & - & 15 & 180 & - & 15 \\
\hline
\end{tabular}

\subsection{The role of $\mathrm{H}_{2} \mathrm{O}$ vapor for effective CNT growth}

A small amount of $\mathrm{H}_{2} \mathrm{O}$ vapor in the CNT growth process reduces amorphous carbon amounts and provided more effective production [32]. $\mathrm{H}_{2} \mathrm{O}$ extends catalyst lifetime during pretreatment and therefore assisting efficient CNT growth.

In this part of the study, under the same parameters, the influences of $\mathrm{H}_{2} \mathrm{O}$ vapor for effective CNT growth on the $\mathrm{Fe} / \mathrm{Al}_{2} \mathrm{O}_{3} / \mathrm{SiO}_{2}$ thin film were investigated. The effect of $\mathrm{H}_{2} \mathrm{O}$ on CNT growth was examined. Pretreatment time was kept constant (15 min) and different $\mathrm{H} 2 \mathrm{O}$ vapor levels were tested. To send $\mathrm{H}_{2} \mathrm{O}$ vapor, a new apparatus was added to the system (Figure 7). A expressed a little amount of $\mathrm{Ar}$ of $\mathrm{H}_{2} \mathrm{O}$ vapor was sent during pretreatment time. B expressed much more $\mathrm{H}_{2} \mathrm{O}$ and $\mathrm{Ar}$ than $\mathrm{A}$, namely $\mathrm{B}$ was more diluted than A. Studied $\mathrm{H}_{2} \mathrm{O}$ vapour amounts were $50^{\circ} \mathrm{C}(\mathrm{A}) / 50^{\circ} \mathrm{C}(\mathrm{A}), \quad 50^{\circ} \mathrm{C}(\mathrm{A}) / 50^{\circ} \mathrm{C}(\mathrm{B})$, $50^{\circ} \mathrm{C}(\mathrm{B}) / 50^{\circ} \mathrm{C}(\mathrm{B}), \quad 50^{\circ} \mathrm{C}(\mathrm{B}) / 50^{\circ} \mathrm{C}(\mathrm{A}), \quad 60^{\circ} \mathrm{C}(\mathrm{A}) / 60^{\circ} \mathrm{C}(\mathrm{A}), \quad 60^{\circ} \mathrm{C}(\mathrm{A}) / 60^{\circ} \mathrm{C}(\mathrm{B})$, $60^{\circ} \mathrm{C}(\mathrm{B}) / 60^{\circ} \mathrm{C}(\mathrm{B}), \quad 60^{\circ} \mathrm{C}(\mathrm{B}) / 60^{\circ} \mathrm{C}(\mathrm{A}), \quad 70^{\circ} \mathrm{C}(\mathrm{A}) / 70^{\circ} \mathrm{C}(\mathrm{A}), \quad 70^{\circ} \mathrm{C}(\mathrm{A}) / 70^{\circ} \mathrm{C}(\mathrm{B})$, $70^{\circ} \mathrm{C}(\mathrm{B}) / 70^{\circ} \mathrm{C}(\mathrm{B}), 70^{\circ} \mathrm{C}(\mathrm{B}) / 70^{\circ} \mathrm{C}(\mathrm{A})$. The results of the $\mathrm{H} 20$ vapor study indicated that the optimum level was $60^{\circ} \mathrm{C}(\mathrm{A}) / 60^{\circ} \mathrm{C}(\mathrm{A})$. Dense CNT growth and narrow average diameters were obtained as the samples grown with $\mathrm{CO}_{2}$ (Table 5). 


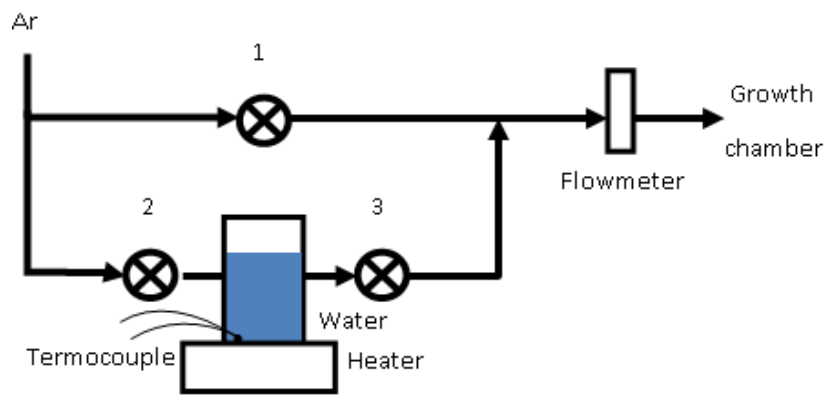

Fig. 7. The setup integrated to send $\mathrm{H}_{2} \mathrm{O}$ vapour in the different amounts $\mathrm{A}$ : valve 1 off, valve 2 ve valve 3 on, $B$ : all valves on, C: valve 1 on, valve 2 ve valve 3 off

Table 4. Catalyst pretreatment and CNT growth parameters and average CNT diameters in the presence of $\mathrm{H}_{2} \mathrm{O}$ vapor (CNT growth temperature: $760{ }^{\circ} \mathrm{C}$ )

\begin{tabular}{cccc}
\hline Sample Name & $\begin{array}{c}\text { Pretreatment } \\
\text { (min.) }\end{array}$ & $\mathrm{H}_{2} \mathrm{O}(\mathrm{p}) / \mathrm{H}_{2} \mathrm{O}(\mathrm{g})\left({ }^{\circ} \mathrm{C}\right)$ & $\begin{array}{c}\text { Ave. diameter } \\
\text { (nm) }\end{array}$ \\
\hline CNT50 & 15 & $60^{\circ} \mathrm{C}(\mathrm{A}) / 60^{\circ} \mathrm{C}(\mathrm{A})$ & 7.01 \\
CNT51 & 15 & $60^{\circ} \mathrm{C}(\mathrm{A}) / 60^{\circ} \mathrm{C}(\mathrm{B})$ & 7.47 \\
CNT52 & 15 & $60^{\circ} \mathrm{C}(\mathrm{B}) / 60^{\circ} \mathrm{C}(\mathrm{A})$ & 8.04 \\
CNT53 & 15 & $60^{\circ} \mathrm{C}(\mathrm{B}) / 60^{\circ} \mathrm{C}(\mathrm{B})$ & 6.80 \\
CNT54 & 15 & $50^{\circ} \mathrm{C}(\mathrm{A}) / 50^{\circ} \mathrm{C}(\mathrm{A})$ & 7.60 \\
CNT55 & 15 & $50^{\circ} \mathrm{C}(\mathrm{A}) / 50^{\circ} \mathrm{C}(\mathrm{B})$ & 9.11 \\
\hline
\end{tabular}

\subsection{Raman Analysis of CNTs}

Raman spectroscopy is an important characterization method to analyze the type and quality of the CNTs. In the Raman spectrum, the G-peak of the CNT sample is a characteristic feature of the graphitic layers placed at $\sim 1580 \mathrm{~cm}^{-1}$. The other characteristic CNT peak is D-peak, an indicative peak of graphitic structure defects such as amorphous carbon, soot and additional carbon structures placed at $\sim 1335 \mathrm{~cm}^{-1}$. The ratios of intensities of D/G peaks represent the quality of CNT samples. Representative Raman spectrum of a CNT sample grown under $760{ }^{\circ} \mathrm{C}$ growth temperature by utilizing $\mathrm{CO}^{2}$ as an oxidizer with pretreatment/growth: $5 / 1(\mathrm{sccm})$ flow rates is given in Fig. 8 . The high $\mathrm{D}$ peak intensity of this sample indicated defects presence in the obtained CNTs structures, $\mathrm{I}_{\mathrm{D}} / \mathrm{I}_{\mathrm{G}}$ was calculated as 0.68 for this sample indicating a significant level of defective carbonous products. A third peak named the radial breathing mode (RBM) being very sensitive to the CNT diameter, giving information about CNT type and placed at between $100-300 \mathrm{~cm}^{-1}$.

RBM peaks were not observed for the CNTs grown by utilizing $\mathrm{CO}_{2}$ as an oxidizer and it means this sample includes multi walled CNTs. CNTs exhibit metallic or semiconducting characteristics depending on their chirality (how the graphitic sheets are rolled) [33] and the splitting of $\mathrm{G}$ band to G- and G+ bands (tangential modes) in Raman spectroscopy highly reveal semiconducting or metallic properties of CNTs [34]. As seen in Fig. 8, G-band did not split G- and $\mathrm{G}+$ bands for the sample grown with $\mathrm{CO}_{2}$ as oxidizer indicating the abundance of metallic multi walled CNTs. 


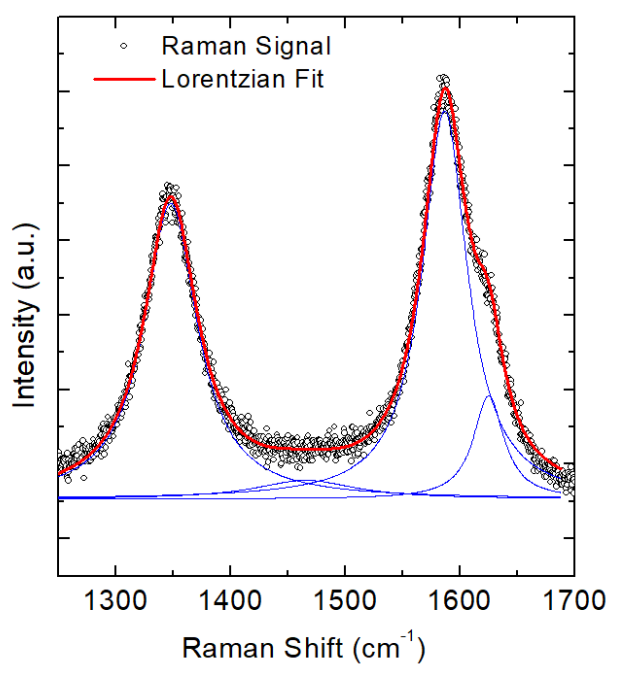

Fig. 8. Raman spectrum of CNT grown under $760{ }^{\circ} \mathrm{C}$ growth temperature by utilizing $\mathrm{CO}_{2}$ as oxidizer with pretreatment/growth: $5 / 1(\mathrm{sccm})$ flow rates

\section{Conclusions}

In this study, the diameter-controlled synthesis of CNTs under different oxidizer gases was discussed. Systematic ways of obtaining controlled nanoparticles from catalyst film to grow the effective CNT were presented with oxidizer gases. Utilized oxidizer gases were $\mathrm{CO}_{2}, \mathrm{O}_{2}$, and $\mathrm{H}_{2} \mathrm{O}$ vapor. Among these oxidizers, the best results were obtained by using $\mathrm{CO}_{2}$ which provided dense CNT growth and narrow CNT diameter range.

Pretreatment time was another parameter affecting CNT quality and diameter. CNTs exposed to a shorter pretreatment time deposited uniformly and had smaller average diameters and showed more density of CNT. Longer pretreatment time caused bigger catalyst particles resulted with larger CNT diameter.

740 and $760{ }^{\circ} \mathrm{C}$ growth temperature of CNT was examined to determine the effect of temperature on CNT diameter and average diameters were significantly decreased for higher temperature.

Overall, obtained CNTs in this study were multi walled CNTs in the diameter range of 5-22 $\mathrm{nm}$. By using oxidizers, a narrow range of metal catalyst sizes and thus narrow diameters of CNTs were maintained. Therefore, diameter-controlled effective production of CNTs was provided. The ability to control over diameters of CNTs makes easier to understand the fundamental properties of CNTs and develop new CNT applications.

\section{Acknowledgments}

This study was supported by The Scientific and Technological Research Council of Turkey (TUBITAK) with the project no. 109T534. We are very thankful to Yusuf Selamet for his support in all the studies mentioned in this work. Additionally, we thank İzmir Institute of Technology Material Research Center for SEM pictures. 


\section{References}

[1] Endo M, Kim Y, Hayashi T, Muramatsu H, Terrones M, Saito R, Villalpando Paez F, Chou S, Dresselhaus M. Nanotube Coalescence Inducing Mode: A Novel Vibrational Mode in Carbon Systems. Small, 2006; 2:1031-1036. https://doi.org/10.1002/smll.200600087

[2] Avouris P. Carbon nanotube electronics and photonics. Physics Today, 2009; 62:34-40. https://doi.org/10.1063/1.3074261

[3] Odom T, Huang J, Kim P, Lieber C. Atomic structure and electronic properties of singlewalled carbon nanotubes. Nature, 1998; 391:62-64. https://doi.org/10.1038/34145

[4] Yuan Z, Huang H, Dang H, Cao J, Hu B, Fan S. Field emission property of highly ordered monodispersed carbon nanotube arrays. Applied Physics Letters, 2001; 78: 3127. https://doi.org/10.1063/1.1372205

[5] Alvi M, Al-Ghamdi A, Husain M. Field emission studies of CNTs/ZnO nanostructured thin films for display devices. Physica B: Condensed Matter, 2017; 521:312-316. https://doi.org/10.1016/i.physb.2017.07.015

[6] Dai H, Hafner J, Rinzler A, Colbert D, Smalley R. Nanotubes as nanoprobes in scanning probe microscopy, 1996. https://doi.org/10.1038/384147a0

[7] Hafner J, Cheung C, Oosterkamp T, Lieber C. High-yield assembly of individual singlewalled carbon nanotube tips for scanning probe microscopies. J. Phys. Chem. B, 2001; 105:743-746. https://doi.org/10.1021/jp0039480

[8] Tachizaki T, Nakata T, Zhang K, Yamakawa I, Taniguchi S.-i. Nanometer-precise optical length measurement using near-field scanning optical microscopy with sharpened single carbon nanotube probe. Ultramicroscopy, 2018; 186:18-22. https://doi.org/10.1016/j.ultramic.2017.12.006

[9] Kong J, Franklin N, Zhou C, Chapline M, Peng S, Cho K, Dai H. Nanotube molecular wires $\begin{array}{llll} & \text { as chemical }\end{array}$ https://doi.org/10.1126/science.287.5453.622

[10] Kauffman DR, Star A. Carbon nanotube gas and vapor sensors. Angewandte Chemie International Edition, 2008; 47:6550-6570. https://doi.org/10.1002/anie.200704488

[11] Chen L, Pang X, Yu Z. Study on polycarbonate/multi-walled carbon nanotubes composite produced by melt processing. Materials Science and Engineering: A, 2007; 457:287-291. https://doi.org/10.1016/i.msea.2007.01.107

[12] Dalton A, Collins S, Razal J, Munoz E, Ebron V, Kim B, Coleman J, Ferraris J, Baughman R. Continuous carbon nanotube composite fibers: properties, potential applications, and problems. Journal of Materials Chemistry, 2004; 14:1-3. https://doi.org/10.1039/b312092a

[13] Futaba D, Hata K, Yamada T, Hiraoka T, Hayamizu Y, Kakudate Y, Tanaike O, Hatori H, Yumura M, Iijima S. Shape-engineerable and highly densely packed single-walled carbon nanotubes and their application as super-capacitor electrodes. Nature Materials, 2006; 5:987-994. https://doi.org/10.1038/nmat1782

[14] Yang L, Zheng W, Zhang P, Chen J, Tian W, Zhang Y, Sun Z. MXene/CNTs films prepared by electrophoretic deposition for supercapacitor electrodes. Journal of Electroanalytical Chemistry, 2018; 830:1-6. https://doi.org/10.1016/i.jelechem.2018.10.024

[15] Jung, M, Yong Eun K, Lee J, Baik Y, Lee K, Wan Park J. Growth of carbon nanotubes by chemical vapor deposition. Diamond and Related Materials, 2001; 10:1235-1240. https://doi.org/10.1016/S0925-9635(00)00446-5

[16] Zhang G, Mann D, Zhang L, Javey A, Li Y, Yenilmez E, Wang Q, McVittie J, Nishi Y, Gibbons J. Ultra-high-yield growth of vertical single-walled carbon nanotubes: Hidden roles of hydrogen and oxygen. Proceedings of the National Academy of Sciences of the United States of America, 2005; 102:16141. https://doi.org/10.1073/pnas.0507064102 
[17] Qu J, Zhao Z, Wang Z, Wang X, Qiu J. Carbon dioxide-assisted fabrication of selforganized tubular carbon micropatterns on silicon substrates. Carbon, 2010; 48:14651472. https://doi.org/10.1016/i.carbon.2009.12.041

[18] Amama P, Pint C, Mcjilton L, Kim S, Stach E, Murray P, Hauge R, Maruyama B. Role of water in super growth of single-walled carbon nanotube carpets. Nano letters, 2008; 9:44-49. https://doi.org/10.1021/nl801876h

[19] Rao F, Li T, Wang Y. Effect of hydrogen on the growth of single-walled carbon nanotubes by thermal chemical vapor deposition. Physica E: Low-dimensional Systems and Nanostructures, 2008; 40:779-784. https://doi.org/10.1016/i.physe.2007.09.185

[20] Kuo D, Su M. The effects of hydrogen and temperature on the growth and microstructure of carbon nanotubes obtained by the Fe (CO) 5 gas-phase-catalytic chemical vapor deposition. Surface and Coatings Technology, 2007; 201:9172-9178. https://doi.org/10.1016/i.surfcoat.2007.04.083

[21] Ince Yardimci A, Yllmaz S, Selamet Y. The effects of catalyst pretreatment, growth atmosphere and temperature on carbon nanotube synthesis using $\mathrm{Co}-\mathrm{Mo} / \mathrm{MgO}$ catalyst. Diamond and Related Materials, 2015; 60:81-86. https://doi.org/10.1016/j.diamond.2015.10.025

[22] Yamada T, Maigne A, Yudasaka M, Mizuno K, Futaba D, Yumura M, Iijima S, Hata K. Revealing the Secret of Water-Assisted Carbon Nanotube Synthesis by Microscopic Observation of the Interaction of Water on the Catalysts. Nano Letters, 2008; 8:42884292. https://doi.org/10.1021/nl801981m

[23] Zhu L, Xiu Y, Hess D, Wong C. Aligned carbon nanotube stacks by water-assisted selective etching. Nano Lett, 2005; 5:2641-2645. https://doi.org/10.1021/nl051906b

[24] Terrado E, Muñoz E, Maser W, Benito A, Martínez M. Important parameters for the catalytic nanoparticles formation towards the growth of carbon nanotube aligned arrays. Diamond and Related Materials, 2007; 16:1082-1086. https://doi.org/10.1016/j.diamond.2006.11.004

[25] Nessim G, Hart A, Kim J, Acquaviva D, Oh J, Morgan C, Seita M, Leib J, Thompson C. Tuning of vertically-aligned carbon nanotube diameter and areal density through catalyst pre-treatment. Nano letters, 2008; 8:3587-3593. https://doi.org/10.1021/nl801437c

[26] Nam TH, Goto K, Yamaguchi Y, Premalal E, Shimamura Y, Inoue Y, Naito K, Ogihara S. Effects of CNT diameter on mechanical properties of aligned CNT sheets and composites. Composites Part A: Applied Science and Manufacturing, 2015; 76:289-298. https://doi.org/10.1016/i.compositesa.2015.06.009

[27] Huang J, Zhang Q, Zhao M, Wei F. Process intensification by CO\&lt;sub\&gt;2\&lt;/sub\&gt; for high quality carbon nanotube forest growth: Doublewalled carbon nanotube convexity or single-walled carbon nanotube bowls? Nano Research, 2009; 2:872-881. https://doi.org/10.1007/s12274-009-9088-6

[28] Futaba D, Goto J, Yasuda S, Yamada T, Yumura M, Hata K. General Rules Governing the Highly Efficient Growth of Carbon Nanotubes. Advanced Materials, 2009; 21:48114815. https://doi.org/10.1002/adma.200901257

[29] Li X, Zhang X, Ci L, Shah R, Wolfe C, Kar S, Talapatra S, Ajayan P. Air-assisted growth of ultra-long carbon nanotube bundles. Nanotechnology, 2008; 19:455609. https://doi.org/10.1088/0957-4484/19/45/455609

[30] Hata K. Water-Assisted Highly Efficient Synthesis of Impurity-Free Single-Walled Carbon Nanotubes. $\quad$ Science, 2004; 306:1362-1364. https://doi.org/10.1126/science.1104962

[31] Hata K, Futaba D, Mizuno K, Namai T, Yumura M, Iijima S. Water-assisted highly efficient synthesis of impurity-free single-walled carbon nanotubes. Science, 2004; 3060:1362. https://doi.org/10.1126/science.1104962

[32] Nikolaev P, Bronikowski M, Bradley R, Rohmund F, Colbert D, Smith K, Smalley R. Gasphase catalytic growth of single-walled carbon nanotubes from carbon monoxide. 
Chemical Physics Letters, 1999; 313:91-97. https://doi.org/10.1016/S00092614(99)01029-5

[33] Talla J, Zhang D, Kandadai M, Avadhanula A, Curran S. A resonance Raman study of carboxyl induced defects in single-walled carbon nanotubes. Physica B: Condensed Matter, 2010; 405:4570-4573. https://doi.org/10.1016/j.physb.2010.08.041

[34] Dresselhaus MS, Dresselhaus G, Saito R, Jorio A. Raman spectroscopy of carbon nanotubes.

Physics

reports,

2005

409:47-99.

https://doi.org/10.1016/j.physrep.2004.10.006 